\title{
Formation of Nano/ultrafine Grain Structure in a Ti-modified 201L Stainless Steel through Martensite Thermomechanical Treatment
}

\author{
Saeed SADEGHPOUR, ${ }^{*}$ Ahmad KERMANPUR and Abbas NAJAFIZADEH \\ Department of Materials Engineering, Isfahan University of Technology, Isfahan, 84156-83111 Iran. \\ (Received on March 7, 2013; accepted on November 19, 2013)
}

\begin{abstract}
The formation of nano/ultrafine grain structure in a Ti-modified $201 \mathrm{~L}$ austenitic stainless steel using the martensite thermomechanical treatment was investigated. Effects of Ti micro-alloy addition on the formation of strain-induced martensite (SIM) during cold rolling and austenite reversion during subsequent annealing were studied. The results showed that the nano-grained Ti-modified $201 \mathrm{~L}$ steel with the average grain size of $45 \mathrm{~nm}$ possessed the yield strength of $1000 \mathrm{MPa}$, ultimate tensile strength of $1330 \mathrm{MPa}$ and total elongation of $42 \%$. Such improvement in mechanical properties of the thermomechanically processed steel is believed to be due to the formation of SIM supplemented with precipitation of Ti carbides.
\end{abstract}

KEY WORDS: martensite thermomechanical treatment; $201 \mathrm{~L}$ stainless steel; Ti; nano/ultrafine grain structure; cold rolling; reversion anneal.

\section{Introduction}

Over the last two decades significant efforts have been made to develop advanced high strength steels with good ductility. ${ }^{1)}$ In this regard, grain refinement from micrometer to submicron or nanometer scale is an important mechanism to improve the strength of metals and alloys. Several different techniques have been utilized to produce ultrafine grained (UFG, $\mathrm{d}<1 \mu \mathrm{m}$ ) and nano grained (NG, $\mathrm{d}<100 \mathrm{~nm}$ ) metals. Severe plastic deformation (SPD) and thermomechanical processes are the main approaches used to produce NG/UFG bulk materials by exploiting large plastic strains. The major methods of SPD such as high pressure torsion (HPT), ${ }^{2,3)}$ equal channel angular pressing (ECAP) ${ }^{4,5)}$ and accumulative roll bonding $(\mathrm{ARB})^{6,7)}$ are well-investigated and have successfully applied to a wide range of metallic alloys. The grain refinement mechanisms of most SPD processes are principally dislocation subdivision, ${ }^{8)}$ twin fragmentation ${ }^{9,10)}$ and phase transformation. ${ }^{11)}$ It is generally agreed that the equilibrium grain size obtained via dislocation subdivision is not on the nanometer scale but generally on the submicron scale. ${ }^{12}$ ) Phase transformations of the materials with low stacking fault energy (SFE) are supplementary mechanisms enabling further refinement of grains to the nanometer scale. ${ }^{11)}$

Austenitic stainless steels (ASSs) have low SFE and may transform to strain-induced martensite (SIM) phase during plastic deformation below the $\mathrm{M}_{\mathrm{d}}$ temperature (as an austenite stability index). A recent thermomechanical process using SIM and its reverse transformation, called martensite treatment, is one of important approaches to fabricate NG/

\footnotetext{
* Corresponding author: E-mail: s.sadeghpour@ma.iut.ac.ir
} DOI: http://dx.doi.org/10.2355/isijinternational.54.920
UFG structure in metastable austenitic steels especially ASSs. ${ }^{13-26)}$ In this approach severe deformation of austenite at room temperature leads to strain-induced transformation of austenite (fcc $\gamma$ ) to martensite (bec $\alpha^{\prime}$ ) and upon annealing, this heavily deformed SIM transforms back to austenite either through a martensitic shear or diffusional reversion mechanisms leading to noticeable grain refinement. ${ }^{27,28)}$ Because of extremely small grain sizes, NG materials exhibit very high strength. However, they are often produced in small quantities and exhibit limited tensile elongation to failure and uniform elongation is even smaller. ${ }^{16,29)}$ The reason for low ductility is plastic instability due to the limited strain hardening arising from the fact that small grains cannot accommodate high density of dislocations. ${ }^{30,31)}$ Several methods have been suggested to improve the uniform ductility such as formation of bimodal grain structure, ${ }^{2)}$ fine particles $^{32)}$ and twins. ${ }^{29)}$

The previous researchers were mainly focused on the formation of NG/UFG structure in the conventional 300 series austenitic stainless steels, ${ }^{16-23)}$ but few studies have been conducted on the grain refinement of 200 series austenitic stainless steel. Recently, Rezaee et al. ${ }^{24,25)}$ have shown that there is a great grain refining potential through martensite treatment for the 201L stainless steel to occur. The main objective of the present work is to investigate the effect of Ti addition on the formation of NG/UFG structure in the 201L stainless steel in order to improve ductility of the NG/ UFG steel.

\section{Experimental Works}

An ingot of Ti-modified 201L steel was prepared in a vacuum induction furnace. The chemical composition of the experimental steel is listed in Table 1. The cast ingot was 
homogenized at $1200^{\circ} \mathrm{C}$ for $12 \mathrm{~h}$ and then hot rolled at $1100^{\circ} \mathrm{C}$ with $85 \%$ reduction in thickness. The hot-rolled plate was solution treated at $1200^{\circ} \mathrm{C}$ for $8 \mathrm{~h}$ followed by water quench. The solution annealed plate was slightly ground to remove the scale on the surface and then cold rolled to different reductions of 5-90\% at room temperature with the strain rate of $0.5 \mathrm{~s}^{-1}$. The reversion annealing was carried out on the $90 \%$ cold-rolled specimens in the range of $750-900^{\circ} \mathrm{C}$ for $60-1800 \mathrm{~s}$.

The standard metallographic techniques and subsequently electro-polishing in an electrolytic bath of $200 \mathrm{ml} \mathrm{HClO}_{4}+$ $800 \mathrm{ml}$ ethanol were employed for the preparation of specimens. To reveal the microstructure, specimens were electrolytically etched in nitric acid $\left(\mathrm{HNO}_{3}\right)$ solution. The microstructural evolution was investigated using a light microscope "Olympus" and a scanning electron microscope (SEM Philips XL30) equipped with energy dispersive spectrometer (EDS). The volume fraction of $\delta$-ferrite and straininduced $\alpha^{\prime}$-martensite phases were determined with a ferritescope (Fischer MP30E). The ferritescope readings were converted to $\alpha^{\prime}$-martensite volume fraction by multiplying with a correction factor of $1.7 .^{33)}$ To avoid errors in determining the volume fraction of SIM phase due to martensite formation during primary preparation, the surface of specimens were electropolished before each test. Phase identification was performed by x-ray diffraction (XRD) technique using Philips X'pert diffractometer. XRD patterns were measured at room temperature in the range of $30^{\circ}-$

Table 1. Chemical composition of Ti-modified 201L stainless steel.

\begin{tabular}{cccccccccc}
\hline Element & $\mathrm{C}$ & $\mathrm{Mn}$ & $\mathrm{Si}$ & $\mathrm{Cr}$ & $\mathrm{Ni}$ & $\mathrm{Ti}$ & $\mathrm{P}$ & $\mathrm{S}$ & $\mathrm{Fe}$ \\
\hline Mass \% & 0.025 & 7.2 & 0.25 & 16.73 & 4.3 & 0.12 & 0.003 & 0.011 & Balance \\
\hline
\end{tabular}

$100^{\circ}$ with $\mathrm{Cu} \mathrm{K} \alpha$ radiation. Flat tensile specimens were cut according to ASTM E8 sub-size standard parallel to the rolling direction. Uni-axial tensile tests were conducted at room temperature using a universal tensile machine with a constant cross-head speed of $5 \mathrm{~mm} / \mathrm{min}$. Hardness of specimens was measured by the Vickers hardness method (HV) applying a $10-\mathrm{kg}$ force.

\section{Results and Discussion}

The optical microstructure of as-cast specimen is illustrated in Fig. 1(a). As can be seen, the structure is consisted of dendritic austenite and interdendritic $\delta$-ferrite. The XRD pattern shown in Fig. 2 confirms the dual phase austeniticferritic microstructure. The amount of $\delta$-ferrite in the as-cast specimen measured by ferritescope was about $19 \%$. It is well known that presence of $\delta$-ferrite in the austenitic stainless steels would decrease hot workability. ${ }^{34)}$ Furthermore, this phase does not change into martensite during deformation, hence can be harmful for thermomechanical process. After homogenizing at $1200^{\circ} \mathrm{C}$ for $12 \mathrm{~h}$, the volume fraction of $\delta$-ferrite was decreased to about $11 \%$ (Fig. 1(b)). The microstructure of the specimen hot rolled at $1100^{\circ} \mathrm{C}$ and subsequently annealed at $1200^{\circ} \mathrm{C}$ for $8 \mathrm{~h}$ is shown in Figs. $1(\mathrm{c})$ and $1(\mathrm{~d})$, respectively. It can be seen that the average grain size has decreased from 85 to $35 \mu \mathrm{m}$ owing to static recrystallization that occur during annealing. ${ }^{28)}$ Moreover the amount of $\delta$-ferrite was significantly decreased to less than $3 \%$.

Figure 3 shows the measured volume fraction of SIM and specimen's hardness as a function of thickness reduction in cold rolling. The formation of SIM is related closely to shear bands which are planar defects associated with the overlapping of stacking faults on $\{111\} \gamma$. According to Talonen et $a l^{35)}$ shear band intersections act as the nucleation sites for
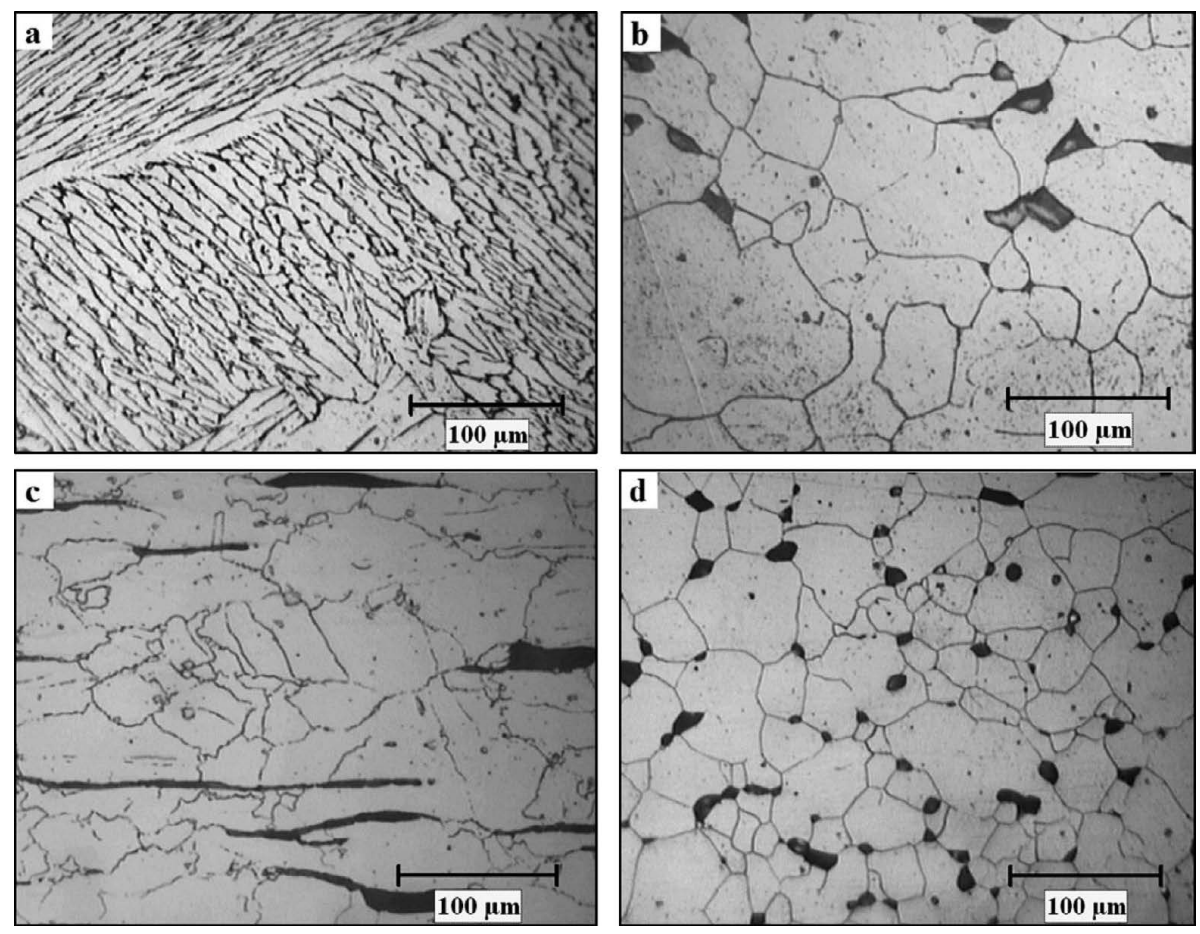

Fig. 1. Optical micrographs of (a) as-cast, (b) as-homogenized at $1200^{\circ} \mathrm{C}$ for $15 \mathrm{~h}$, (c) as-hot-rolled, and (d) as-solution annealed at $1200^{\circ} \mathrm{C}$ for $8 \mathrm{~h}$ specimens. 


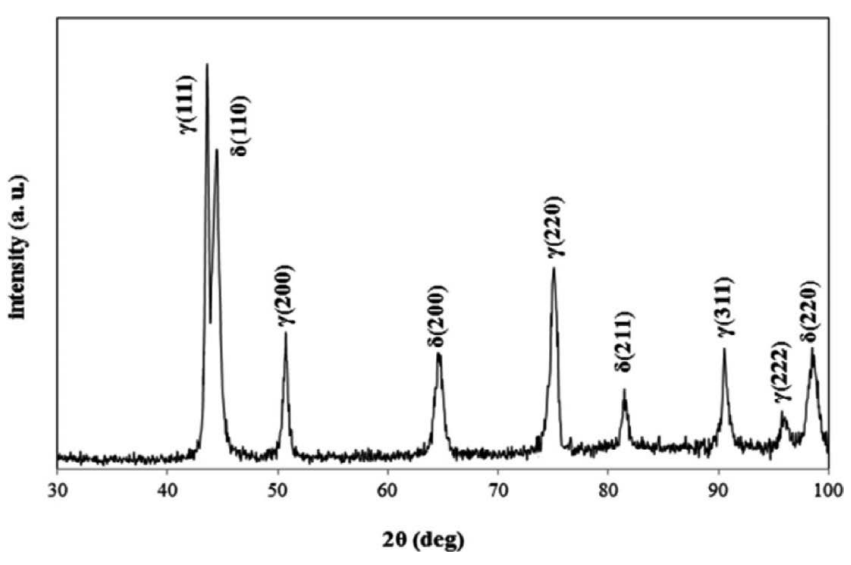

Fig. 2. XRD pattern of the as-cast specimen.
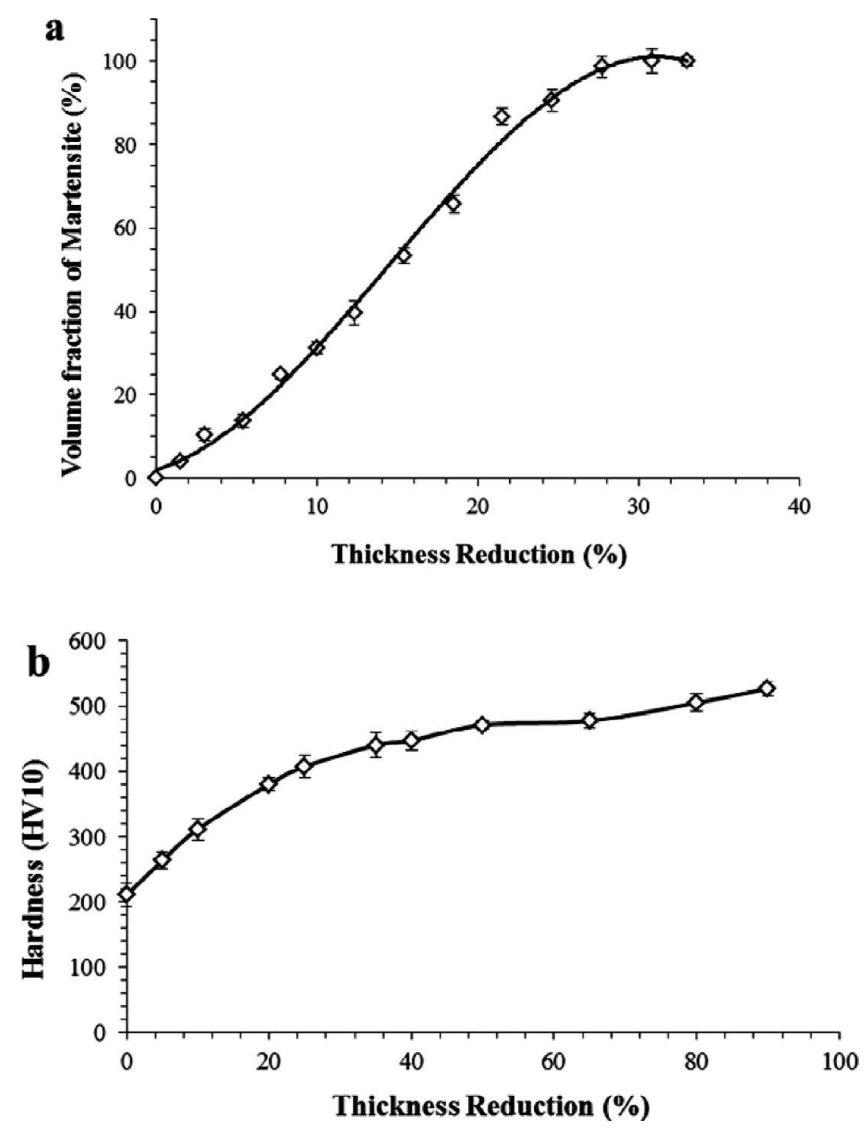

Fig. 3. Effect of thickness reduction on (a) the martensite formation, and (b) hardness values.

$\alpha^{\prime}$-martensite, and the formation of shear bands is a necessary precursor for SIM transformation. Formation of shear bands is controlled by stacking fault energy (SFE) thus SFE plays an important role in determining austenite stability. From Fig. 3, it can be seen that the volume fraction of SIM is increased with the amount of thickness reduction and is reached to saturation $\left(\varepsilon_{\mathrm{s}}\right)$ by approximately $30 \%$ cold rolling. The $\varepsilon_{\mathrm{s}}$ can be as an austenite stability index and plays an important role in the formation of ultrafine grain size. Further cold rolling above $30 \%$ reduction deforms the SIM itself and thereby increases density of crystal defects. It has reported $^{24)}$ that, standard 201L stainless steel saturated at the thickness reduction of $40 \%$ whereas in the present Timodified $201 \mathrm{~L}$ steel saturation was occurred in $30 \%$ thick-

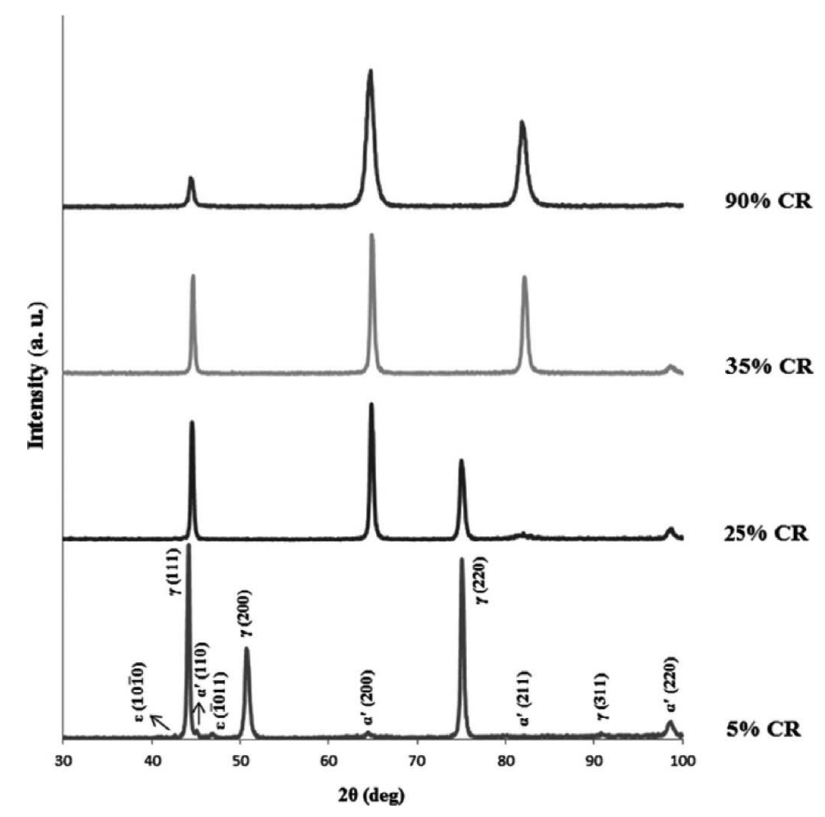

Fig. 4. XRD patterns of the cold rolled specimens.

ness reduction. In fact Ti-modified 201L steel has a lower $\mathcal{E}_{\mathrm{s}}$ owing to lower SFE. It has been reported ${ }^{36)}$ that SFE is decreased by addition of Ti to 316 stainless steel. Moreover, it is known that $\mathrm{Ti}$ is a strong ferrite stabilizer and strong carbide former. The addition of $\mathrm{Ti}$ can therefore remove carbon from solid solution thus reducing the stability of austenite and enhancing the susceptibility for formation of SIM. As can be seen in Fig. 3(b), the hardness variation is faster for strains before the saturation limit due to the formation of SIM during cold rolling. After saturation, the hardness is further increased by dislocation density and consequent strain hardening during the deformation. ${ }^{26}$ )

Figure 4 shows XRD patterns of the cold rolled specimens with $5 \%$ to $90 \%$ reduction in thickness. Weak $\varepsilon(10 \overline{1} 0)$ and $\varepsilon(\overline{1011})$ peaks can be detected from the diffraction pattern of the $5 \%$ cold rolled specimen confirming the formation of $\varepsilon$-martensite in the earlier stages of deformation. With further reduction to $25 \%$, the $\varepsilon$-martensite disappeared and the intensities of $\alpha^{\prime}$ peaks increased. In $35 \%$ reduction, the $\alpha^{\prime}$ peaks are observed solely. With increasing the cold reduction to $90 \%, \alpha^{\prime}$ peaks are broaden owing to an intense increase in crystal defects.

The XRD patterns for the samples annealed at $800^{\circ} \mathrm{C}$ and $900^{\circ} \mathrm{C}$ for $60 \mathrm{~s}$ are shown in Fig. 5. In the $90 \%$ cold rolled (no annealed) specimen, the microstructure is fully $\alpha^{\prime}$ martensite (Fig. 4). Upon annealing, the $\alpha^{\prime}$ phase is reversely transformed to $\gamma$ phase. The microstructure of the specimen annealed at $800^{\circ} \mathrm{C}$ for $60 \mathrm{~s}$ is composed of $\alpha^{\prime}$-martensite and $\gamma$-austenite. The reversion is completed at $900^{\circ} \mathrm{C}$ for same duration and the microstructure is fully $\gamma$-austenite. Hence the higher temperature can lead to a faster reversion due to diffusion-controlled nature of reversion. The reverse transformation mechanism can be different even at the identical annealing temperature depending on alloy chemistry. Tomimura et al. reported that diffusive reverse transformation happens at the high ratio of $\mathrm{Cr}$ to $\mathrm{Ni}$ in metastable $\mathrm{Fe}-$ $\mathrm{Cr}-\mathrm{Ni}$ ternary alloys. But to account for the effects of other alloying elements such as Mn, Mo, Si and C, Somani et al. 


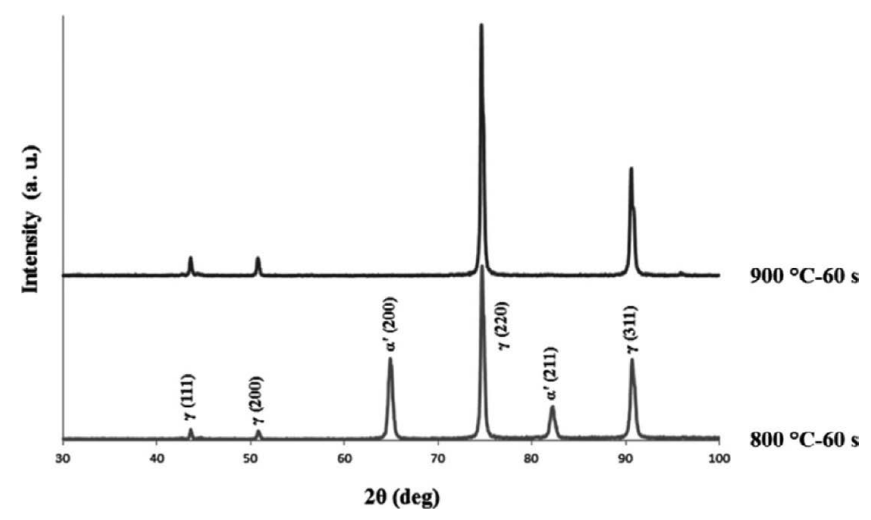

Fig. 5. XRD patterns of the specimens annealed for $60 \mathrm{~s}$ at different annealing temperature.

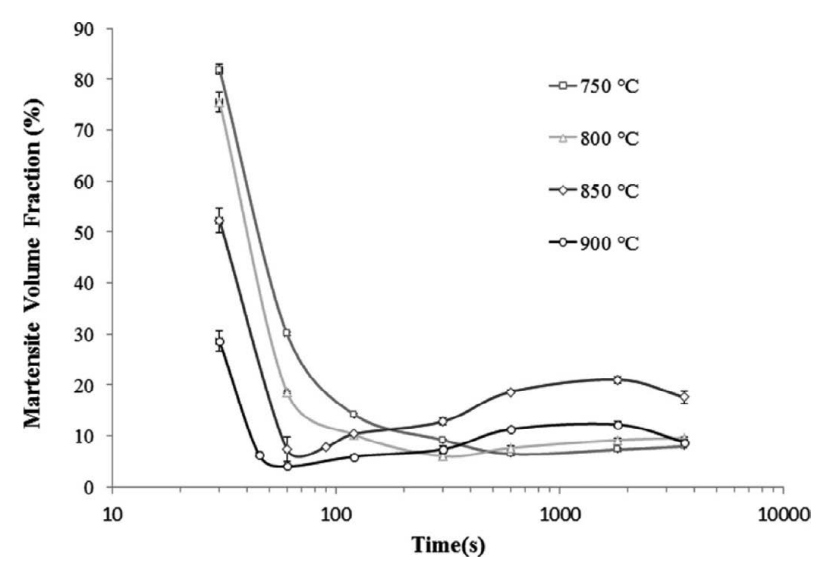

Fig. 6. Martensite volume fraction as a function of reversion annealing time at various temperatures.

used $\mathrm{Cr}_{\mathrm{eq}}$ and $\mathrm{Ni}_{\mathrm{eq}}$ values instead of $\mathrm{Cr}$ and $\mathrm{Ni}$, respectively.

Figure 6 shows the variation of martensite volume fraction, after $90 \%$ reduction in thickness followed by reversion annealing at various temperatures, versus annealing time. Samples annealed at $750^{\circ} \mathrm{C}$ and $800^{\circ} \mathrm{C}$ for $30 \mathrm{~s}$ show a relatively small austenite phase fraction revealing these annealing conditions are not sufficient to drive the $\alpha^{\prime} \rightarrow \gamma$ reversion. Further annealing at $750^{\circ} \mathrm{C}$ and $800^{\circ} \mathrm{C}$ for $600 \mathrm{~s}$ leads to significant $\alpha^{\prime} \rightarrow \gamma$ reversion. This data indicate that the $\alpha^{\prime} \rightarrow \gamma$ reversion should be driven by a diffusioncontrolled mechanism where an activation energy barrier prevents austenite nucleation at low annealing temperatures and short annealing durations, but higher annealing temperatures or longer annealing durations result in austenite nucleation and growth. As is seen in Fig. 6, at lower temperatures longer annealing time was taken to complete reversion, while the reversion rate is much faster at higher temperatures and is relatively complete at $850^{\circ} \mathrm{C}$ and $900^{\circ} \mathrm{C}$ after $60 \mathrm{~s}$ because the diffusion rate always accelerates as the temperature is raised above the transformation temperature. At higher temperatures a secondary increase in martensite content can be seen in Fig. 6. This behavior that has also reported in several previous studies ${ }^{15,18,26)}$ can be attributed to the increasing of $\mathrm{M}_{\mathrm{s}}$ as a result of carbide formation. Carbide or nitride precipitation at high temperature can lead to depletion of $\mathrm{C}$ or $\mathrm{N}$ in the reverted austenite and consequently, some reverted austenite may again transform back to martensite. Since Ti is a strong carbide former, it is not
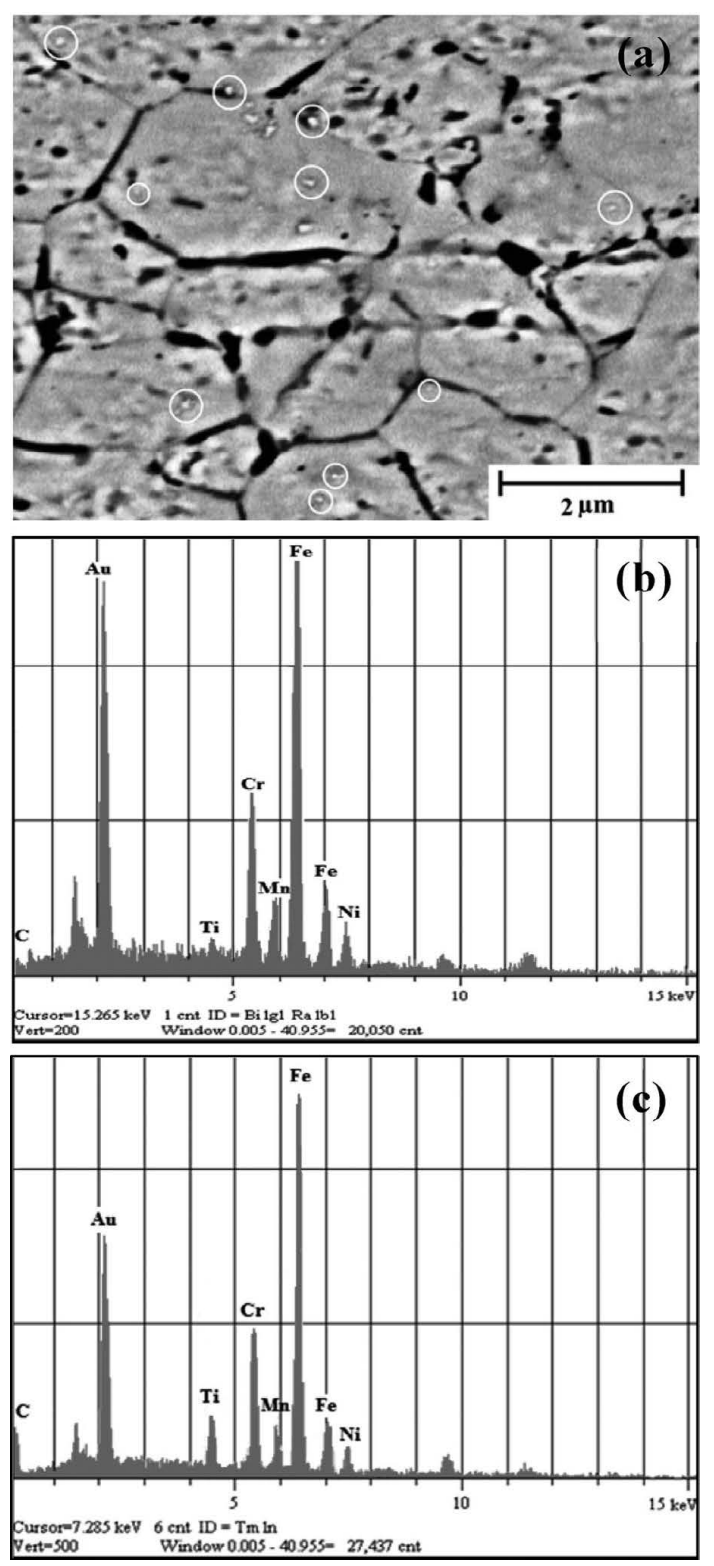

Fig. 7. SEM image of carbides (a), with EDS analysis of the austenitic matrix (b), and corresponding carbides in the specimen annealed at $900^{\circ} \mathrm{C}$ for $1800 \mathrm{~s}$.

unexpected for $\mathrm{TiC}$ precipitation to occur. Carbide particles were detected in the annealed samples. Annealing at $900^{\circ} \mathrm{C}$ for $1800 \mathrm{~s}$ led to a significant increase in the size of carbides and consequently simplified precipitates observation. Carbide particles of about $70 \mathrm{~nm}$ were observed in the specimen annealed at $900^{\circ} \mathrm{C}$ for $1800 \mathrm{~s}$ (Fig. 7(a)). A comparison of the EDS spectra from the particles and matrix shows an increase in $\mathrm{C}$ and $\mathrm{Ti}$ content in the second phase particles (Figs. 7(b) and 7(c)). The Au peak in the EDS spectra is from the Au coat applied on the surface of SEM sample. The results confirm that the particles may be TiC that cannot be characterized in SEM images in short annealing times.

The maximum reversion for the Ti-modified $201 \mathrm{~L}$ steel was occurred at $900^{\circ} \mathrm{C}$ (Fig. 6), while it was seen at $850^{\circ} \mathrm{C}$ for $201 \mathrm{~L} \mathrm{steel} .^{20)}$ This difference can be attributed to the precipitation of $\mathrm{TiC}$ which retards the reversion process. This retardation in the reversion treatment is related to the pinning effect of carbides. ${ }^{20}$ The effect of reversion annealing time at $900^{\circ} \mathrm{C}$ on the hardness values is presented in Fig. 8 . 
As shown, the hardness is first decreased and then this trend is reverted after $60 \mathrm{~s}$. Decreasing of the hardness is related to the lower density of dislocation, lower volume fraction of martensite and an increase in austenite grain size caused by increasing the annealing time. The secondary hardness increase is attributed to an increase in the volume fraction of martensite due to the formation of carbides as mentioned before. Obtained results suggest that the annealing at $900^{\circ} \mathrm{C}$ for $60 \mathrm{~s}$ is the optimum annealing condition for obtaining a fully reverted NG/UFG structure for Ti microalloyed 201L stainless steel.

The microstructure of specimens annealed at $900^{\circ} \mathrm{C}$ for different annealing times are shown in Fig. 9. Because of very fine microstructure in the specimens, a lot of grains are removed from the surface of specimen during the etching and lead to such a rough microstructure. Given that, it was difficult to identify the grain boundaries from the SEM micrographs especially in the nanostructured samples (annealed at $900^{\circ} \mathrm{C}$ for $60 \mathrm{~s}$ and $120 \mathrm{~s}$ ), in these cases the diameter of individual grains with approximately well-

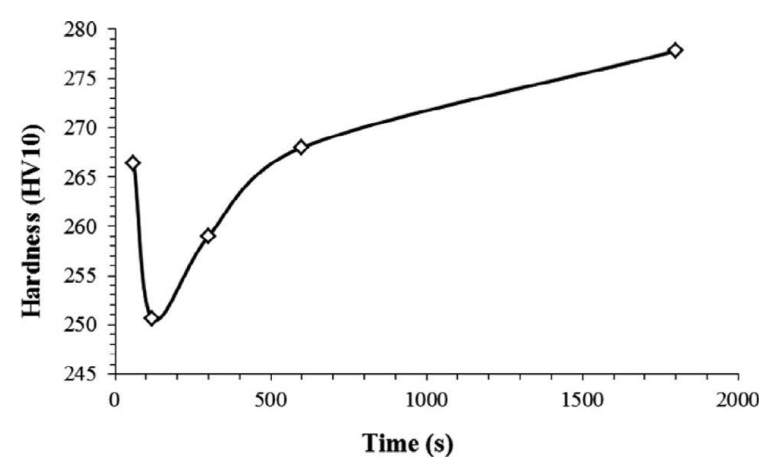

Fig. 8. Variation of hardness with reversion annealing time at $900^{\circ} \mathrm{C}$. defined shape was measured so that the presented grain sizes are the average of at least 100 measurements (5 SEM micrographs and 20 measurements per micrograph). For example, some of these measurements are presented in Fig. 9(a). After annealing for $60 \mathrm{~s} \mathrm{(Fig.} \mathrm{9(a)),} \mathrm{the} \mathrm{microstructure}$ was consisted of equiaxed $\gamma$-grains with average grain size of $45 \mathrm{~nm}$. Figures 9(a)-9(d) show no significant grain growth at $900^{\circ} \mathrm{C}$ for annealing times up to $600 \mathrm{~s}$ so that after annealing for $120 \mathrm{~s}, 300 \mathrm{~s}$ and $600 \mathrm{~s}$, the austenite grain sizes are $56 \pm 11,93 \pm 20$ and $421 \pm 71 \mathrm{~nm}$, respectively. Meanwhile, the grain size for $201 \mathrm{~L}$ stainless steel annealing at $900^{\circ} \mathrm{C}$ for $600 \mathrm{~s}$ has been reported about $2300 \mathrm{~nm} .^{25)}$ The very small increase in grain size at $900^{\circ} \mathrm{C}$ for duration up to $600 \mathrm{~s}$ seems to indicate that the presence of $\mathrm{TiC}$ carbides, which grow and coarsen during annealing, plays an important role in suppressing grain growth.

The engineering stress-strain curves of the $90 \%$ cold rolled and annealed specimens at $900^{\circ} \mathrm{C}$ are shown together with that of initial solution annealed specimen in Fig. 10. The strength and elongation of the $90 \%$ cold rolled specimen is about $1900 \mathrm{MPa}$ and $2 \%$, respectively. However, upon the reversion and formation of $\mathrm{NG}$ structure, the strength is decreased and ductility is increased sharply. The NG specimen possesses a very high yield strength $(\sim 1000 \mathrm{MPa})$, six times higher than that of the initial coarse-grained steel and a very high ultimate tensile strength $(\sim 1330 \mathrm{MPa})$. This improvement is also accompanied by $42 \%$ total elongation for the NG specimen. For vast majority of the NG/UFG metals, ductility is nowhere close to their characteristic ductility in the coarse-grained form. However, the present results show that despite the significant grain refinement (from $35 \mu \mathrm{m}$ to $45 \mathrm{~nm}$ ) taken place by the thermomechanical treatment, the NG/UFG Ti-modified 201L stainless steel possesses higher ductility. This further improvement in ductility is believed to be attributed to the
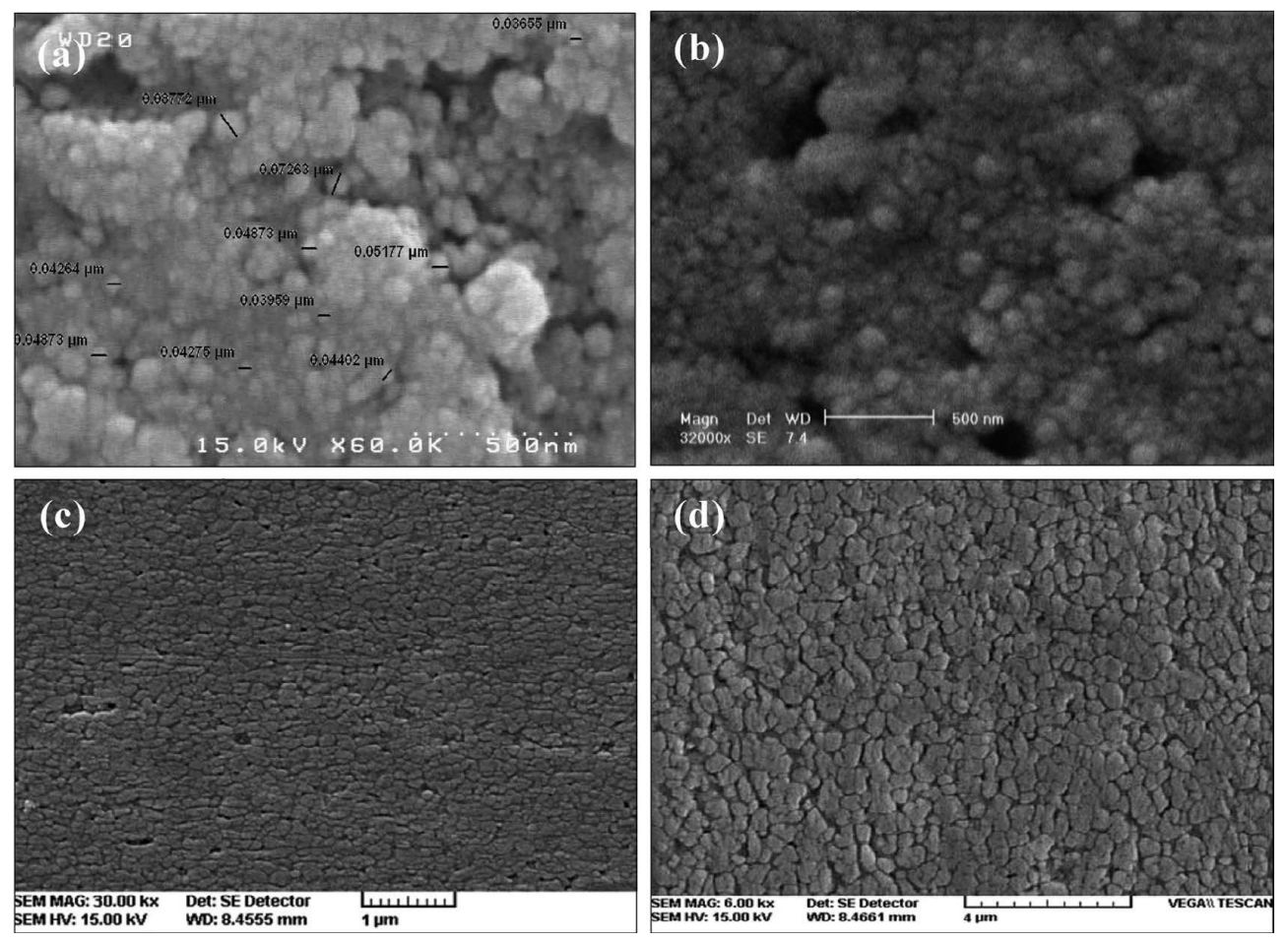

Fig. 9. SEM micrograph of the sample annealed at $900^{\circ} \mathrm{C}$ for (a) $60 \mathrm{~s}$, (b) $120 \mathrm{~s}$, (c) $300 \mathrm{~s}$ and (d) $600 \mathrm{~s}$. 


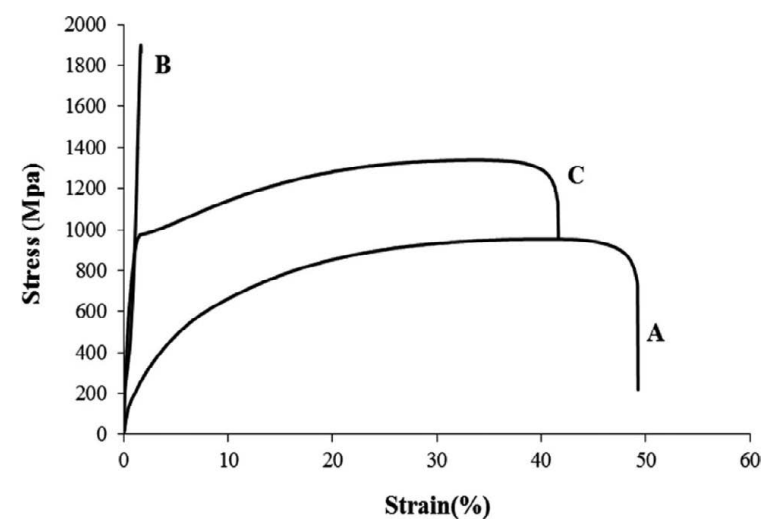

Fig. 10. Engineering stress-strain curves of (A) solution annealed specimen (grain size: $35 \mu \mathrm{m}$ ), (B) $90 \%$ cold-rolled specimen, and (C) reversion annealed specimen at $900^{\circ} \mathrm{C}$ for $60 \mathrm{~s}$ (grain size: $45 \mathrm{~nm}$ ).

precipitation of $\mathrm{TiC}$. The fine precipitates are deemed to improve mechanical properties through promotion of SIM transformation due to the depletion of solute atoms near the precipitates. More work is in progress to investigate the mechanism of such behavior.

\section{Conclusion}

Based on the results obtained in this study, the following conclusions can be summarized.

(1) The saturation strain for the formation of $\alpha^{\prime}$ martensite during cold rolling of Ti-modified 201L stainless steel was found at about $30 \%$ reduction in thickness, showing a promoting effect on the formation of SIM.

(2) The highest volume fraction of reverted austenite was achieved after annealing at $900^{\circ} \mathrm{C}$ for $60 \mathrm{~s}$. For further annealing times above $60 \mathrm{~s}$, the thermally-induced martensite was formed during water quenching.

(3) In the specimen annealed at $900^{\circ} \mathrm{C}$ for $60 \mathrm{~s}$, the grain size of $45 \pm 12 \mathrm{~nm}$ with more than $95 \%$ austenite was achieved.

(4) It was found that presence of $\mathrm{TiC}$ precipitates could retard the reversion process and suppressed grain growth in further annealing times.

(5) The NG Ti-modified 201L stainless steel with the average grain size of $45 \mathrm{~nm}$ exhibited a good combination of high strength of $1330 \mathrm{MPa}$ and high elongation to failure of $42 \%$.

\section{REFERENCES}

1) H. Dong, X. Sun, W. Cao, Z. Liu, M. Wang and Y. Weng: On the Performance Improvement of Steels Through $\mathrm{M}^{3}$ Structure Control, ed. by Y. Weng, H. Dong and Y. Gan, Advanced Steels, Springer, New York, (2011), 35.

2) R. Z. Valiev: Mater. Sci. Eng. A, 234 (1997), 59.

3) R. Z. Valiev, N. A. Krasilnikov and N. K. Tsenev: Mater. Sci. Eng. A, 197 (1991), 35.

4) V. M Segal: Mater. Sci. Eng. A, 338 (2002), 331.

5) R. Z. Valiev and T. G. Langdon: Prog. Mater. Sci., 51 (2006), 881.

6) Y. Saito, H. Utsunomiya, N. Tsuji and T. Sakaki: Acta Mater., 47 (1999), 579.

7) N. Tsuji, Y. Saito, H. Utsanomiya and S. Tanigawa: Scr. Mater., 40 (1999), 795.

8) Y. Iwahashi, Z. Horita, M. Nemoto and T. G. Langdon: Acta Mater., 46 (1998), 3317.

9) Y. S. Li, N. R. Tao and K. Lu: Acta Mater., 56 (2008), 230.

10) S. Qu, X. H. An, H. J. Yang, C. X. Huang, G. Yang and Q. S. Zang: Acta Mater., 57 (2009), 1586.

11) C. X. Huang, Y. L. Gao, G. Yang, S. D. Wu, G. Y. Li and S. X. Li: J. Mater. Res., 21 (2006), 1687.

12) A. Y. Chen, H. H. Ruan, J. Wang, H. L. Chan, Q. Wang, Q. Li and J. Lu: Acta Mater., 59 (2011), 3697.

13) A. Di Schino, M. Barteri and J. M. Kenny: J. Mater. Sci. Lett., 21 (2002), 751.

14) Y. Ma, J. E. Jin and Y. K. Lee: Scr. Mater., 52 (2005), 1311.

15) D. L. Johannsen, A. Kyrolainen and P. J. Ferreira: Metall. Mater. Trans. A, 37 (2006), 2325.

16) Y. K. Lee, J. E. Jin and Y.Q. Ma: Scr. Mater., 57 (2007), 707.

17) R. D. K. Misra, B. Ravi Kumar, M. Somani and P. Karjalainen: Scr. Mater., 59 (2008), 79.

18) M. Eskandari, A. Kermanpur and A. Najafizadeh: Metall. Mater. Trans. A, 40 (2009), 2241.

19) M. Eskandari, A. Najafizadeh and A. Kermanpur: Mater. Sci. Eng. A, 519 (2009), 46.

20) M. Karimi, A. Najafizadeh, A. Kermanpur and M. Eskandari: Mater. Charact., 60 (2009), 1220.

21) R. D. K. Misra, S. Nayak, P. K. C. Venkatasurya, V. Ramuni, M. C. Somani and L. P. Karjalainen: Metall. Mater. Trans. A, 41 (2010), 2162.

22) F. Forouzan, A. Najafizadeh, A. Kermanpur, A. Hedayati and R. Surkhialiabad: Mater. Sci. Eng. A, 527 (2010), 7334.

23) S. Rajasekhara, L. P. Karjalainen, A. Kyrolainen and P. J. Ferreira: Mater. Sci. Eng. A, 527 (2010), 1986.

24) A. Rezaee, A. Kermanpur, A. Najafizadeh and M. Moallemi: Mater. Sci. Eng. A, $\mathbf{5 2 8}$ (2011), 5025.

25) A. Rezaee, A. Najafizadeh, A. Kermanpur and M. Moallemi: Mater. Design, 32 (2011), 4437.

26) M. Moallemi, A. Najafizadeh, A. Kermanpur and A. Rezaee: Mater. Sci. Eng. A, $\mathbf{5 3 0}$ (2011), 378

27) K. Tomimura, S. Takaki, S. Tanimoto and Y. Tokunaga: ISIJ Int., 31 (1991), 721.

28) K. Tomimura, S. Takaki and Y. Tokunaga: ISIJ Int., 31 (1991), 1431.

29) R. Z. Valiev: Nat. Mater., 3 (2004), 511.

30) E. Ma: Scr. Mater., 49 (2003), 663.

31) C. C. Koch: Scr. Mater., 49 (2003), 657.

32) P. G. Sanders, P. G. Eastman and J. R. Weertman: Acta Mater., 45 (1997), 4019.

33) J. Talonen, P. Aspegren and H. Hanninen: Mater. Sci. Technol., 20 (2004), 1506.

34) T. Ogawa and E. Tsunetomi: Weld. J., 61 (1982), 82

35) J. Talonen and H. Hanninen: Acta Mater., 55 (2007), 6108.

36) A. F. Padhilha, R. L. Plaut and P. R. Rios: ISIJ Int., 43 (2003), 135. 